Article

\title{
Stakeholder Visions for Biodiversity Conservation in Developing Countries
}

\section{Ademola A. Adenle ${ }^{1,2, *}$, Casey Stevens ${ }^{1}$ and Peter Bridgewater ${ }^{1}$}

1 Institute for the Advanced Study of Sustainability, United Nations University (UNU-IAS), 5-53-70 Jingumae, Shibuya-ku, Tokyo 150-8925, Japan; E-Mails: casey.c.stevens@gmail.com (C.S.); peter@global-garden.net (P.B.)

2 Blavatnik School of Government, University of Oxford, Oxford OX1 2JD, UK

* Author to whom correspondence should be addressed; E-Mail: adenle@unu.edu or aadenle@gmail.com; Tel.: +81-45-221-2367; Fax: +81-45-221-2303.

Academic Editor: Vincenzo Torretta

Received: 16 August 2014 / Accepted: 23 December 2014 / Published: 29 December 2014

\begin{abstract}
The 2014 Conference of the Parties (COP 12) for the Convention on Biological Diversity (CBD) was another step on the road to achieving the Aichi Targets the CBD agreed in 2010. It was also a key step on the way to making progress towards the vision of a more balanced relationship between people and the rest of biodiversity by 2050 . Many key issues were left for this COP by negotiators from COP 11 and earlier meetings; such as settling financial issues, articulating clearly the Aichi Targets for national implementation by 2020 , or providing clear guidance on capacity-building for developing states. This paper utilizes 22 stakeholder interviews taken at the 2012 Hyderabad COP to develop discussion of ongoing issues in the CBD negotiations. These interviews yielded a number of tractable policy opportunities available for the 2014 Conference to create significant space for developing countries to contribute effectively to global achievement of the Aichi Targets. Breakthroughs and developments at the COP, despite the inevitability of some difficult discussions, will be provided by developing country perspectives. Despite that potential traction, Ministers at the high-level segment noted that progress towards the Aichi targets is insufficient and recognizing there was still much to do on resource mobilization, reaffirmed their commitment to mobilize financial resources from all sources for the effective implementation of the Strategic Plan for Biodiversity 2011-2020. As we enter the second half of the 2011-2020 decade, developing countries must be placed at the center of efforts to improve sustainable use, conservation and benefit sharing of biodiversity around the world.
\end{abstract}


Keywords: aichi targets; biodiversity conservation; financial mechanism; developing countries

\section{Introduction}

Negative changes to Biodiversity, especially species loss, continue at disturbing pace around the world, but biodiversity loss in developing countries is a primary and unique environmental challenge [1,2]. Governance decisions made at the global level in the near future will prove crucial for reducing biodiversity loss and helping to harmonize human interactions with the ecosystems in developing countries. Most of the discussions have focused on how to increase funding for biodiversity projects around the world and on targeting existing aid toward ecosystems in the most need. This research paper approaches the issue in a different way with one central question: what decisions can be made in the near term which will spur long-term action in developing countries?

This was a question of pressing concern for the eleventh and very recently twelfth Conference of the Parties of the Convention on Biological Diversity (CBD). In 2010, parties to the CBD agreed to establish a set of global targets (the Aichi Targets) to help stem biodiversity loss, as the cornerstone to the Strategic Plan for the decade. Some of these targets set 2015 as their endpoint while others were set at 2020. This paper serves to provide the responses from high-level practitioners to develop some focal points in response to the question. The first part will provide some background for the Aichi Targets and the 2011-2020 Strategic Plan for the CBD. The second part will discuss how the respondents for this study were selected and the methodology of collecting their responses. The final part will collect the responses and organize them around key policy-relevant issues. While the responses are not exhaustive of opinions, they provide an excellent window for exploring and engaging with key issues of biodiversity governance in the next few years.

\section{Progress in Global Governance for Biodiversity}

The Aichi Targets are a set of 20 different objectives under five broad goals for biodiversity conservation, management and benefit sharing, to achieve in the 2011-2020 period. The goals are ambitious, many have robust possible measurement devices, and they can serve as important focal points for national, local, and nongovernmental organization (NGO) efforts. The Aichi Targets follow from the earlier 2010 targets of the CBD which were developed in 2002 at the World Summit on Sustainable Development (WSSD) and later at COP6. In 2006 these targets were integrated into Goal 7 of the Millennium Development Goals (MDGs). This ambitious goal sought "to achieve by 2010 a significant reduction of the current rate of biodiversity loss at the global, regional and national level as a contribution to poverty alleviation and to the benefit of all life on Earth" [3,4]. In fact, the 2010 targets did not spur state action or result in significant improvement in the state of biodiversity $[5,6]$ but the political space that the targets provided created new networks of action and a focus on advancing global biodiversity indicator systems: notable amongst these are the IUCN Countdown 2010 Initiative and the Biodiversity Indicators Partnership (BIP) of UNEP's World Conservation Monitoring Center [7]. Since 2004, additional efforts have led to the creation of the Intergovernmental Platform on Biodiversity and Ecosystem Services (IPBES) in 2012, which has potential to provide 
additional technical underpinning needed to achieve the targets. The impact of these various partnerships has yet to be clearly seen in transforming biodiversity policy. When it became clear to the parties that the 2010 targets were not going to be achieved, efforts began to develop a new set of goals with attached targets and indicators. Two key interventions have created a more robust system of governance for the 2011-2020 Strategic Plan periods which the previous decade did not have. One of these was The Economics of Ecosystems and Biodiversity (TEEB) initiative which was developed by the European Commission and UNEP. The TEEB initiative aimed to develop a framework for integrating economic and ecosystem analysis to find effective ways to value biodiversity [8]. The TEEB initiative presented reports at COP9 and COP10 which were used by a variety of different actors in the negotiations [9]. A second, more important, development was the final achievement of an Access and Benefit Sharing (ABS) protocol, also called the Nagoya Protocol, as part of the CBD. Although a goal from the outset, progress was slow and ineffectual until final agreement at COP10. This breakthrough added an important tool for evaluating and enabling benefit sharing of biodiversity and is thus crucial in biodiversity governance at all, especially local, scales. While 2020 is set as the date for most target outcomes, Target 16 (the entry into force for the Nagoya Protocol on Access and Benefit Sharing) and Target 17 (the development of updated National Biodiversity Strategies and Action Plans-NBSAPs) were set for completion by 2015. Both of these targets were considered "mission-critical" for progress in the later years. While progress on ratification of the Nagoya Protocol was achieved in 2014, only 10\% of countries had revised their NBSAPs by June 2014.

The financing issue was similarly emphasized in the COP10 negotiations and formed a key issue in the subsequent COP11 discussions in Hyderabad. However, even after COP12 the financing issue continues largely unresolved. Citing the post-2008 financial crisis donor countries have been unwilling to agree to increases in aid. The varied funding needs for different developing countries have not been effectively identified either. In one assessment by McCarthy et al. [10], it was estimated that current biodiversity funding would need to be expanded by about $800 \%$ for effective progress on the Aichi Targets to be achieved. While prioritizing and targeting of aid may help in preventing loss in some of the most threatened ecosystems [11], significant new funding is necessary. Full progress on the Aichi Targets requires efforts on Target 20 which aims for "the mobilization of financial resources for effectively implementing the Strategic Plan for Biodiversity...should increase substantially from the current levels".

At the COP11 in 2012 parties agreed to make assessment and creation of key targets for biodiversity financing a key topic at the COP12 (Decision XI/4). 2014 offers a unique opportunity thus to make progress on the financing progress. The GEF Replenishment negotiations concluded in March 2014 and should benefit inter alia the CBD. At the Ministerial session at COP 12, Ministers noted that progress towards the Aichi targets is insufficient, and reaffirmed their commitment to mobilize financial resources from all sources for the effective implementation of the Strategic Plan for Biodiversity 2011-2020. Yet this is little change form COP 11 in 2012.

COP12 discussions took place in an important period for global environmental and development governance, including negotiations on Sustainable Development Goals At COP 12 Ministers also welcomed the importance placed on biodiversity in the outcome document of the Open Working Group on SDGs, and called for further integration and mainstreaming of biodiversity in the post-2015 development agenda, inviting the UN General Assembly to integrate the Aichi targets in this agenda. 
Rather than seeing this all these complex developments or non-developments as constraining efforts at COP12, stakeholders in the CBD used the opportunity to develop creative solutions to their own problems. This paper uses stakeholder interviews with some of these individuals form COP 11, to develop a set of policy relevant avenues for attention which can offer improved prospects for achieving Aichi Targets by developing countries.

\section{Challenges for Biodiversity Governance}

Biodiversity loss is driven most significantly by land-use decisions [12,13]. Freshwater and coastal ecosystems especially are becoming increasingly exposed to threats of climate change and land conversion (e.g., agriculture and bioenergy crops), pollution, migration and infrastructure development [14]. According to the Millennium Ecosystem Assessment, climate change is a threat to ecosystem services including water, wild plants and forestry in Southern and Eastern Africa. In addition, agriculture is responsible for much of the biodiversity loss in Sub-Saharan Africa, South-East Asia and Latin America. Moreover, the fast growing population in developing countries is also worsening the situation as pressure continues to mount on biodiversity due to rise in demand for food, energy and habitat conversion. In addition, different pressures from corporate globalization have been linked to commercial activities in countries with "biodiversity hotspots".

It has been argued that majority of the biodiversity-implicated products that come from developing countries end up in industrialized countries. Five selected developing countries such as Honduras, Madagascar, Sri Lanka, Malaysia and Papua New Guinea, combined represent $60 \%$ of all domestically recorded biodiversity threats due to export activities [15]. According to Lenzen et al. (2012), the main final destination of biodiversity-implicated products is the USA, EU and Japan. Furthermore, [16] show that biodiversity loss is directly linked to a number of water-related trade activities (e.g., fishing) and demand from developed countries. This tends to amplify driving forces of change and increasing pressures on ecosystem services globally. Although growing concern related to commercial biodiversity - implicated products can only be resolved at the international meetings when all hands are on deck. While the access and benefit sharing of Nagoya protocol introduced by the CBD regarding sovereign right over the use of biological resources is only just slowly emerging, debates over access and ownership of biodiversity will continue to generate heated discussion.

The central challenge for global biodiversity governance remains in how to create multi-level action on local land-use decisions around the world. However, policy institutions and funding remain limited to spur and connect action around the world.

Hence, the nub of the policy question of this report is, how can we make decisions in the near term which will spur long term action around the world? As developing countries hold the greatest quantity of biodiversity at all levels and as policy innovation is likely to be greatest in those countries in the short-term, the main focus of our discussion is on developing countries. The CBD operates as an umbrella organization on biodiversity issues conducting its own governance activities but also connected with the other biodiversity conventions. It was opened for signature at the Rio de Janeiro Summit in Brazil 1992 and saw quick ratification by many countries. In 2002, the WSSD (Johannesburg, South Africa), major stakeholders including political leaders agreed to "to achieve by 
2010 a significant reduction of the current rate of biodiversity loss at the global, regional and national level" (COP 6 Decision VI/26) [17].

There were several barriers to achieving this goal in various countries and the issues were particularly acute in many developing countries. While the goal was agreed at the international level, it did not include engagement of relevant stakeholders in its design or agreement at the national level. While many countries were constructing their first or second NBSAPs, these were handled primarily by the national focal points without always including multiple actors from throughout society [18]. Some authors $[19,20]$ have argued that failure to integrate and communicate development needs inevitably place limits on biodiversity conservation in many developing countries. According to Swiderska (2002), development policy and planning does not reflect win-win options that support both biodiversity and development objectives that affect poor rural communities, thereby limiting the efforts of national governments. In fact, capacity development provided by the UN agencies made a minimal impact as national government policy failed to emphasize development needs [18]. While attempts have been made to link biodiversity conservation with human development and poverty alleviation [21], the lack of understanding between poverty and conservation linkages undermine support for biodiversity conservation at the national levels [18,20].

The issues of win-win policy options and trade-offs raises key questions about the resilience of biodiversity policies that do not solve development challenges and the ethics of excluding the poorest from the benefits of biodiversity conservation. Ostrom's challenge on "fortress conservation theory" argued that the efforts of local people in managing common pool resources should be recognized as key to robust and adaptive institutional frameworks [22]. A recent study also follows this line of argument by applying a framework that emphasized the need to "change the existing approach to biodiversity as a linked social-ecological issue" which requires effective governance arrangement that prioritizes local communities to strengthen biodiversity policy [23]. A growing body of literature [24,25] has reported policy fragmentations around regulation, market-based incentives mechanism and expansion of protected areas with a view to halting biodiversity loss as part of conservation paradigm. However, barriers including poor alignment of local knowledge, value and weak market-based instruments continue to undermine current efforts. There is need to understand factors determining the success or failure of institutions and how they interact between actors and their interdependence in order to govern biodiversity sustainably [26]. These authors proposed traditional farmer use-perspective approach that incorporates motivation and interest of actors in biodiversity, which are fundamental elements of transaction that can offer adequate governance solution. While use-perspective approach is at initial stage, further work is required before it can be operational for research. Similarly [27] recommended decision-system theory based on practical biodiversity conservation program initiated by farmer groups can enhance conservation decision particularly in farm trading business and land ownership decision-system. Given smallholder farming practices in many developing countries, this approach may be difficult unless a simplified model is produced to suit their systems.

At the same time, the time frame for the 2010 goal did not allow full assessment, monitoring, or development of clear national strategies for biodiversity protection [28,29]. According to [29], it was important to "incorporate an independent, transparent, credible and robust scientific assessment of the potential success of such policies", but the lack of sufficient time was part of the reasons why this 
policy process was unsuccessful. The Aichi Targets aim to deal with this problem by increasing monitoring capacity and by focusing on focused goals which allow clear progress to proceed. Two outstanding and acknowledged challenges for the 2011-2020 Strategic Plan and the Aichi Targets are to expand financing for biodiversity and expand the stakeholders involved in the governance of the problem. Estimates put the cost for biodiversity between US\$20 billion and US\$25 billion per year to achieve global conservation effectively [30]. However, how developing countries are prioritized in getting access to these funds so as to implement biodiversity policy effectively and achieve biodiversity targets are yet to be clarified.

Moreover, lack of empirical data in this regard makes it difficult to know how funding can be channeled to help developing countries that require most assistance. A recent analysis by Waldron [31] suggests that most highly underfunded countries are from developing countries with biodiversity hotspot but require a coordinated effort to reduce biodiversity loss particularly in conflict prone countries. Although the governance quality will determine whether to allocate mixed conservation and development aid by the donors as less politically stable countries might not be able to attract this kind of aid [32]. Domestic environmental budgets may respond to local political concerns and not be targeted towards areas with significant importance in preventing biodiversity loss (Nelson 2009, this may also be the case with global biodiversity aid which may prioritize countries with severe biodiversity need, but not necessarily areas within those countries with severe need, see: Holmes, Scholfield, and Brockington 2012). In addition, expanded stakeholders and creating new points of engagement for scientists and practitioners in developing countries could be a key area for development and transformation [33]. These challenges will be particularly pressing in the period after the 2014 Conference of the Parties as funding will need to materialize soon to have significant impacts and actors will have to be engaged in order to start policy implementation.

\section{Methodology}

\subsection{Expert Viewpoint Elicitation}

This study is based on the qualitative analysis of expert elicitations for the management and conservation of biodiversity in developing countries. We refer to as persons who have specialized knowledge and a wealth of experience on biodiversity issues either through research or participation at the various levels of national government and international meeting such as Conference of the Parties. The open-ended questions were used in the face-to-face interviews to elicit expert viewpoints on a wide range of issues through qualitative approach [34]. Experts' elicitation can use a semi-structured or unstructured interview to assess their subjective judgment on tasks which require to be assessed [35]. The key aspect of an expert elicitation particularly with regard to decision-making and generating ideas for future needs does not allow consensus as it is often done within a group [36]. However, rather it provides insight into the current diversity of agreement and disagreement that may exist within an expert community but communication to the public fora.

These attributes implicated expert elicitation as appropriate methodology for this study because of our interest in seeking the views of experts that can provide relevant information on biodiversity conservation in developing countries. As a result, our methodology relied on a semi-structured 
interview (using open-ended questions) with attention to topical relevant issues that could benefit from the viewpoints of the experts. The interviewees were allowed to discuss freely and clarified answers to questions asked (e.g., "Can you please provide an example?" or "why is it relevant?" or "tell me what you know about it through your experience"). This specific probe used during the interviews did not only reduce the impact of personal biases but helped focus on actual real life examples of biodiversity.

\subsection{Stakeholder Selection}

We used the opportunity of COP11 meeting to interact with as many relevant stakeholders as possible through face-to-face interview as guided by interviews questions (i.e., relevant to the goals set for 2020) described in Appendix. The criteria used to select the participants are based on demonstrated expertise and research in biodiversity and involvement in national or global conservation policy development which was confirmed prior to the interview. Therefore, individuals selected were the ones who met requirements as mentioned above before the interview. Interview participants were selected and interviews conducted by the lead author. Participants led their delegates or represented their organizations and in some cases they were involved in working groups during the event. Essentially, these are policymakers whose key roles and contributions are very significant to decision-making at the COP11 meeting. Therefore, there is need to gain insight into perspective of individual policymaker in decision-making as premature consensus about the knowledge and skills for efficiency and strategic decision is often avoided when experts are interviewed differently [35].

First the individual was approached and an appropriate time was scheduled for the interview during the COP 11 meeting. Twenty-two detailed individual interviews were conducted with the national delegates, including ministers, directors and representatives of non-governmental organizations (NGOs) on the management and conservation of biodiversity in developing countries as described in Table 1.1 to 3 individuals were interviewed from 9 different countries, European Commission and NGOs. 2 to 3 individuals had to be interviewed from the same country or organization as recommendations were often made by first interviewee to interview other experts from their country who could provide additional information in response to questions they were unable to answer. The lead author conducted all the interviews on site at the eleventh meeting, COP 11, October 2012, Hyderabad, India. Interviews lasted between 30 and $60 \mathrm{~min}$.

Several organizations and individuals representing their countries were approached for the interviews but not all including the head of UN agencies were available due to other commitments at the COP 11 meeting. As many as 50 individuals were approached but only 22 granted the interviews (Table 1). However, the paper benefited from the content of many side events, including speeches delivered by the Prime Minister of India, Vice-President of World Bank, the Executive Secretary of CBD, the Executive Secretary of United Nations Environment Programme (UNEP) and the CEO of the Global Environment Facility at the conference. Moreover, notes were taken simultaneously at the meetings. Stakeholders' views were reported anonymously except in a few cases permission where their permission allowed us to reveal their participant organization. 
Table 1. List of countries and participating organizations that contributed to this paper $(N=22)$.

\begin{tabular}{|c|c|c|}
\hline Countries/Organizations & Position & Affiliations/Department \\
\hline \multirow{2}{*}{ China } & (1) Director & Ministry of \\
\hline & (2) National Focal Point & Environmental Protection \\
\hline \multirow{3}{*}{ Brazil } & (3) Minister and Head of the delegation & \\
\hline & (4) National Secretary of Biodiversity & Ministry of Environment \\
\hline & (5) Senior Advisor and Director & \\
\hline \multirow{2}{*}{ Kenya } & (6) Director General & Ministry of Environment, Water \\
\hline & (7) Deputy Director & and Natural Resources \\
\hline \multirow{2}{*}{ Bolivia } & (8) Senior Advisor and Head of Delegation & Ministry of Foreign Affair and \\
\hline & (9) National Focal Point & Ministry of Environment and Water \\
\hline \multirow{2}{*}{ Ghana } & (10) Professor (National Biodiversity Committee) & Ministry of Environment, \\
\hline & (11) Director & Science and Technology \\
\hline Canada & (12) Director & Environment \\
\hline Japan & (13) Director & Ministry of Environment \\
\hline \multirow{2}{*}{ South Africa } & (14) Deputy Minister & Minister of Water and \\
\hline & (15) Director & Environmental Affairs \\
\hline \multirow{2}{*}{ India } & (16) Director & \multirow{2}{*}{ Ministry of Environment and Forest } \\
\hline & (17) Chairman & \\
\hline European Commission (EC) & (18) Biodiversity Policy Officer & Environment \\
\hline $\begin{array}{c}\text { International Union for } \\
\text { Conservation of Nature (IUCN) }\end{array}$ & (19) Director & Global Policy \\
\hline \multirow{2}{*}{ Nature Conservancy } & \multirow{2}{*}{ (20) President and CEO } & Management and \\
\hline & & Environmental Strategy \\
\hline \multirow{2}{*}{ Conservation International } & (21) President & Biodiversity and Ecosystem \\
\hline & (22) Director & Services Policy \\
\hline
\end{tabular}

\subsection{Data Organization and Analysis}

Interviews were tape-recorded and contemporaneous notes were taken. Following the interviews, audio recordings were transcribed immediately and coded systematically (using qualitative data analysis software, Hyper Research 2007), whilst considering verbatim quotes, key points and phrases used. Every key information and important quote from more than 20,000 words transcribed was used for the analysis below. The biodiversity topics that we focus on in this study are those that received a lot of attention in response to our questions during the interviews. For example, "beyond target 11", chosen as a sub-topic is an example where participants felt that a lot of activities are going on in many developing countries. Therefore omission of other targets in the discussion is not a deliberate attempt in this paper but rather we put together what attracts most attention in an effort to achieve goals set for the year 2020 .

\subsection{Limitation}

While not a fully representative set of participants nor inclusive of all stakeholders, the individuals interviewed allowed for the development of key insights into progress on implementation of the Aichi Targets, as well as wider progress on CBD implementation. The absence of other stakeholder groups 
including representatives from some of the biodiversity-rich countries may be a limitation. But non-inclusion is due to one of the reasons mentioned in Section 2.2 as efforts made to speak to them proved futile. Moreover, some of the participants interviewed have worked across many developing countries, therefore, their views may not necessarily be different from those that were not interviewed. For example, one of the participants mentioned that he has visited 150 countries and worked in 20 countries, mostly megadiverse countries.

\section{Findings}

\subsection{Beyond Target 11}

One of the significant arguments made by multiple respondents was the need to strive towards significantly expanded protected area systems, particularly focused on crucial areas for biodiversity protection. Respondents argued that efforts could be significantly increased on Aichi Target 11 (protected areas covering at least $17 \%$ of land and 10\% of coastal and marine areas), Target 12 (zero extinction), and Target 14 (safeguarding essential ecosystems and accounting for women, indigenous, and rural livelihoods). This point is emphasized by one respondent: "Look at Madagascar I've been there 90 times in the last 28 years, $100 \%$ of the primates are endemic, $80 \%$ of the plants are endemic, $99 \%$ of the frogs are endemic... amazing endemism I mean, not just at the species level but at the genus level, family level, so you have whole evolutionary lineages there...90\% is gone, the worst erosion you'll see anywhere...If you don't protect that last $10 \%$, you could lose a major chunk of global biodiversity".

Similar to Madagascar, Tunisia, Libya, Liberia, Ivory Coast, Cape Verde, Ghana, Gabon and Guinea are African countries with significant hotspots and very high endemism that could result to an enormous loss of biodiversity if action is not taken. Parallel to these hotspots, major tropical underdeveloped areas also have high biodiversity, particularly in Amazon, the Congo Forest Block, New Guinea and the woodlands of Southern Africa were also mentioned among respondents as key areas. However, one respondent noted that although tropical forests have lower levels of fragmentation than do some of ecosystems, they are seeing significant level of loss. Respondents emphasized a strong focus on hotspots and high biodiversity wilderness areas with the highest level of endemism should be clearly developed in NBSAPs if extinction is to be prevented and Target 12 met. Respondents also emphasized that efforts should try and exceed the Aichi Targets. One respondent stated: "In order to succeed, there is urgent need to push for $25 \%$ as opposed to $17 \%$ set in Nagoya despite some progress made with Aichi Target 11" and having already 15\% terrestrial in protected areas in many developing countries [37]. This goal may fit in the overall project of the 2011-2020 Strategic Plan as building towards a better biodiversity world by 2050. Although the majority of African countries currently have between $9 \%$ and $10 \%$ of terrestrial in protected areas under IUCN red list [38]. African countries such as South Africa, Kenya, Rwanda and Tanzania have relatively good legislative framework and have a large number of protected areas, particularly in Tanzania. Respondents argue that it will be difficult to achieve Aichi Targets in some African countries due to complex political situation, limited institutional capacity and weak legislative framework. 
Those countries which have reached and exceeded the global Aichi Target land percentage may offer instructive lessons. In Bolivia, the government recognized the need to put in place political and institutional mechanism to ensure more protected areas are covered, thereby achieving the global targets by the year 2020. For example, in Bolivia, one of their top priorities is to evaluate the level of involvements of indigenous and local communities in view of concept of Mother Earth [39], and incorporating appropriately important elements into the framework under the third pillar of national conservation project. However, the Bolivia representative disagreed with the concept of green economy as part of implementation processes for Aichi biodiversity targets.

Some advanced developing countries such as China, Brazil and India have already reached or surpassed the land target. According to one of China's representatives "more than 35 priority project areas have been identified for conservation which occupy $24 \%$ of the whole Chinese territory and we are already at target $17 \%$ and looking beyond the global target to achieve $18 \%$ ". However, he acknowledged that China is $2 \%-3 \%$ short of global target $10 \%$ for the marine protected area. Brazil has a strong national biodiversity council, as one of the few countries that lived up to the goals of 2010 biodiversity targets, is making efforts to achieve the Aichi targets by the year 2020 and beyond.

Other countries face similar problems. Brazil has already approved 18 out of 20 Aichi targets. Brazil has 5 major biomes (Caatinga, Cerrado, Pantanal, Amazon and Atlantic Forest) with almost $17 \%$ of its terrestrial (Aichi target 11) under protected areas as explained by the national focal point. Although a very high proportion of the protected areas is in the Amazon. The rest of major biomes only have an average of $3 \%$ in terms of protected areas. The Brazilian representatives felt that there is need for Brazil to double its effort in promoting and implementing legislative framework in the less protected areas, particularly where the important landscapes are absent in the areas under protection (the Pantanal and the southern part of Brazil). The Indian representatives also shed some light regarding government efforts in conserving key biodiversity areas. According to the representative, India has one of the strongest biodiversity progras in Asia. For example, the Indian National Green Corps has a strong network throughout the country that promotes and educates students to the issues related to the importance of biodiversity conservation. India is also one of the few countries that lived up to the goals of 2010 biodiversity target with almost $20 \%$ of terrestrial under protected areas, above the global target of $17 \%$. However, according to the interview, coastal wetlands are one of the least protected areas which require government attention.

While progress has been steady on Target 11 and the world has gone forward significantly in creating a "well connected systems of protected areas and other effective area-based conservation measures", challenges certainly remain [40]. To turn protected areas into effective tools to prevent and reduce biodiversity loss will require increased funding, mainstreaming protected areas into larger landscapes (including cities, agricultural landscapes, etc.), and improving marine protected systems. Unfortunately, effectively connected systems of protected areas are very rare [41] and many hotspots and ecoregions have received insufficient attention [31]. Marine protected areas present a specific challenge in terms of need for technology for monitoring, integration into near-coastal economic activity, and funding to identify and define the area [42]. The issue of identifying ecological important marine protected areas yielded significant debate at COP 11, but progress has been stalled with many 
negotiators stating that the need for better science in identifying and managing these marine areas is necessary for action.

\subsection{Improved Biodiversity Action}

One problem with biodiversity action around the world is that it often done in politically expedient ways rather than focusing on potential biodiversity impact. For example, [43] explain that "Present conservation efforts bias toward lands that are high, cold, dry, or otherwise far from people" which limits the impact of these conservation policies on improving all forms of biodiversity. Respondents were well aware of these problems and diagnosed the problem in a variety of different ways: Low priority for biodiversity in many governments, a problem making the importance of biodiversity clear, and developing frameworks for protecting ecosystem services. Policy solutions promoted including a host of different education efforts (making clear the connections between biodiversity, ecosystem services, and the well-being of people in poverty).

Mainstreaming was set as one of the primary goals to develop from the Strategic Plan and the focus on the Aichi Targets (most explicitly in Aichi Target 2). The CBD Secretariat module on mainstreaming specifies that this aims for "the integration of the conservation and sustainable use of biodiversity in both cross-sectorial plans... and in sector-specific plans such as agriculture, fisheries, forestry, mining, energy, tourism, transport and others. It implies changes in development models, strategies and paradigms. Mainstreaming is not about creating parallel and artificial processes and systems, but about integrating biodiversity into existing or new sectorial and cross-sectorial structures, processes and systems" [44]. While positive cases of mainstreaming are highlighted in discussions (for example in CBD Decision XI/3) there is not a clear template for applying this in diverse policy contexts. Progress on mainstreaming is limited even in developed countries, but in contexts of more limited resources and less technology for implementing integration have more significant limitations.

Respondents were concerned that biodiversity was not receiving the priority it deserved in poverty reduction discussions. Some claimed that this was a problem of communicating the benefits of biodiversity to the public see: [45]. One participant from Africa, for instance, describes her observation about awareness: "Government still have a lot of work...I don't think we have convinced the public as there is still a very poor understanding of what biodiversity is... why it is relevant across the board from rural to urban." Although some respondents from emerging economies mentioned that the public is becoming increasingly aware of the importance of biodiversity through the media, respondents felt that the lack of basic understanding of the role of biodiversity in sustaining agricultural systems and its values in terms of the food, water, air, climate stability, and physical protection that it provides, remain a big challenge in developing countries (In the Biodiversity Barometer, China and Brazil citizens could correctly define biodiversity at higher percentages than any other countries including Western Europe and the U.S. In contrast, India and Peru had the lowest levels in the survey for correctly defining biodiversity [46] Union for Ethical BioTrade. Biodiversity Barometer 2013. Amsterdam: UEBT; 2013). Respondents added that the relationship between ecosystem services and biodiversity conservation has yet to gain awareness and attention among local communities and national policymakers. One of the respondents and a leading expert on conservation remarked that "the world at 
large still sees biodiversity as a side issue...we don't even have a whole lot of ministers here as far as I know, and I don't think we have any heads of state...that is indicative of the importance that they give to the issue".

This low priority may partially be a result of the way that concern for biodiversity is communicated. Some respondents argued that the value of biodiversity is often lowered because of the focus on biodiversity loss rather than ecosystem services. One participant commented "If I tell you that there is an opportunity to unlock potential for development, for jobs through beneficiating biodiversity, whether it's through protected areas, water security, agro-biodiversity...then there is hope of gain and interest...unless we as a sector switch our language and our mind-sets to something more positive, we may as well go home because we have not succeeded as a sector with the language of loss". This group of respondents emphasized that phrasing biodiversity in development friendly manner can be important in persuading all stakeholders, particularly at the local community levels to participate meaningfully in conservation approach. According to this respondent "if they say you over-harvest fish, that's not development...how about saying, if we protect fish, that's development". Therefore, the change of two words in that sentence can spur hope and future that comes with opportunity rather than threat.

Beyond changing the focus, there was no clear policy direction suggested for improving protection of ecosystem services in rural communities. Poverty is largely responsible for biodiversity loss in developing countries. Since there is linkage between biodiversity conservation and poverty reduction [21], assessing socio-economic indicators relating to ecosystem service and biodiversity conservation is fundamental to poverty reduction [47]. One important question raised among respondents is: how do you encourage someone not to cut down forests when there is no other livelihood option? One respondent demonstrated this with an example: "Most of the time, they know. Fishermen realize, when they catch less fish than usual, that they are exploiting the supply...but they don't have another option and you can't just blame them, you have to find out the rationale behind the behavior of people and come up with solutions...the solution has to come from internal policies, it has to adjust to social and cultural levels so they can take ownership of it".

Other respondents identified the lack of an appropriate policy dialogues to facilitate incentives for protection of biodiversity at local levels. Developing a biodiversity system which maximizes the protection of ecosystem services is a particular challenge for developing countries [24,48]. The development of niche product markets, such as payment for ecosystem services (PES), can provide incentive to farmers to conserve and manage ecosystem services sustainably are beginning to emerge [24,25]. However, capacity development to implement this type of conservation approach varies from country to country and limited market opportunities must be overcome before rural poor can benefit from the approach. Respondents felt the need to integrate key socio-economic indicators (including access to health and education) and define the criteria by broader stakeholder deliberation in measuring the success of conservation. TEEB advice and projects adhering to its framework have expanded in a variety of different countries. Similarly, the ABS system established by the Nagoya Protocol may help developing countries in these efforts.

A crucial step in the process is updated and strengthened NBSAPs by developing countries. Some respondents argued that, apart from advanced developing countries such as China, Brazil, and India which are developing unique NBSAPs, most developing countries lack the capacity to develop well-structured plans. When explaining the failure for implementation of earlier NBSAPs to help 
achieve the 2010 biodiversity target, respondents raised the issue of very non-participatory processes of planning. NBSAPs are usually coordinated by the Ministry of the Environment as the focal point in the CBD and because of limited capacity, they rarely involved large number of stakeholders. One respondent explained that "in most cases, typically what happens is that you have an environment ministry that has the CBD focal point who goes back home, gets a little bit of GEF money, or UNDP money and writes a national biodiversity action plan probably in consultation with a few other government agencies and environmental NGOs, and then you get a nice plan and it sits on the shelf, because the plan itself is owned by the environment ministry". NBSAPs often do not involve other ministries (such as planning, finance, agriculture, water, fisheries, energy/power, etc.) and this limited the degree of support for the implementation of the NBSAPs. In addition, this may prevent biodiversity as an issue from making inroads into social and economic policy. One respondent said that "When we talk about the three pillars of sustainable development: economic, social, and environment...you always hear, 'balance among the three', which is usually a way of saying the environment is going to lose out, because when we then talk to the trade or finance ministry, we don't hear about a balance among the three, because there are no environment people there...so it always gets less political attention".

This NBSAP problem may be part of a larger problem of institutional capacity and political will. Legislation which could aid mainstreaming of biodiversity in other economic areas is lacking in most developing countries. For example, in Brazil, one respondent felt that lack of clear legislation on research and development of genetic resources within the ministries was responsible for the failure to engage research institutes and multinational company on the international regime of access and benefit sharing for potential bioproducts. In addition, in any cross-sectorial or cross-ministerial engagements, environmental ministries may be disadvantaged. One respondent explained that the experts, trained $\mathrm{PhD}$ and Master's degree holders, find it very difficult to pursue policies and are disempowered in NBSAP discussions as a result.

These experiences, mainly from the first generation of NBSAPs, made clear how the capacity can constrain designing appropriate plans. The key policy question is how to help the next generation of NBSAPs to encourage wider planning process without making the process needlessly cumbersome? While there was no direct answer, respondents agreed on the broad terms that the NBSAPs for the Aichi targets need to be comprehensive and have a participatory framework that defines clear rules, indicators and works towards mainstream biodiversity in multiple sectors.

\subsection{Mobilizing Financial Resources for Biodiversity}

Mobilizing financial resources for protected areas is a key issue in discussions. These resources can build partnerships and strengthen institutions for biodiversity conservation. All respondents agreed that much effort is needed by various stakeholder groups to deploy and coordinate financial resources effectively so as to achieve the expected biodiversity targets.

Each country faces separate funding challenges. The majority of current biodiversity spending is focused on biodiversity in the U.S., Europe, and China. Latin America, Africa, and the remainder of Asia receive significantly less funding, from both domestic and international sources, than these other countries [49]. Developed countries face significant political limitations on increasing their 
biodiversity aid from the very low levels. However, integration of biodiversity with other issues offers opportunities for improved funding flows. For example, biodiversity aid from developed to developing countries increased in the first years of the Aichi Targets era but was largely the result of a doubling of aid on these nexus projects rather than increasing funding for biodiversity projects [50]. However, the funding challenges in the developing world are also different depending on the country. Latin America, for example, has built the most extended protected area system in the world, but in order to transform that system into an effective tool for reversing biodiversity loss it is estimated that there will have to be a doubling of funding [51]. In contrast, many other developing countries need financial assistance to develop second generation NBSAPs that translate the Aichi Targets into national policy [52]. This is reflected in the distribution of countries which have quickly created revised NBSAPs since the Nagoya meeting (as required in Aichi Target 17). By January 2014, 20 countries had submitted revised NBSAP: ten OECD countries, four are in Latin America, and six are from non-OECD countries in Europe and Asia. None of the early revisions come from Africa or the Middle East.

However, some respondents felt that generating income for biodiversity conservation should start from the local communities. This group of respondents argue that focusing on value of biodiversity at the local levels can lead to investments that generate income to conserve biodiversity and ecosystem services. Moreover, recognizing the value of renewable natural capital or biodiversity like tropical forest in terms of the benefits it provides to humankind or people in the local communities can help transform financing biodiversity conservation. For example, the payment of fees for access to ecosystem services such as hunting, ecotourism, bioprospecting and protected areas with high ecological value can create local ecosystem service economies. They felt that it could be a useful source of income to manage and maintain protected areas if supporting policies and procedures outline clearly the practicalities of the benefits. They argue that supporting policies should target financial rewards while at the same time generating income from biodiversity conservation. Moreover, the European Union representative mentioned that as part of TEEB projects, it would be interesting to gain more understanding on income generated through the payment of fees and therefore it is worth investigating as additional funds for conservation in developing countries. By doing so, it could help in understanding the scope of monetary valuation that is associated with the biodiversity at the local level.

The sources of finance for biodiversity conservation vary significantly from country to country. Respondents mentioned that governments that appreciate the value of biodiversity and the role ecosystem services play in underpinning economic growth and poverty reduction tend to invest more money than governments with less priority biodiversity conservation. One respondent gave an example: "Some of these big countries like the BRICS countries are powerful, advanced economic forces in the world...for example, China, Brazil and some of other South America countries are putting far more money than they are getting from outside assistance, hundreds of millions of dollars into conservation activities within their borders...some of the poorer countries, like Madagascar, they are almost totally dependent on foreign aid". Respondents mentioned that lack of a clear framework to implement biodiversity projects undermines the ability of governments to attract funding from donors in developing countries - particularly African countries. For example, in Madagascar, a total of \$54 million was provided by the World Bank and the Global Environment Facility (GEF) in 2011 to 
extend their environment program (including biodiversity projects), yet the government has not developed a plan to spend the money. One respondent argued that the GEF-5 process from 2010 to 2014 did not have a clear focus for disbursement of its funds and many important countries were left out. From that perspective they saw GEF-6 as a key opportunity for making clearer and simpler disbursement procedures for developing countries.

However, in addition to national funding, respondents saw the lack of funding from OECD countries to support their biodiversity efforts as a major hurdle in achieving the Aichi Targets. A further problem is that the aid provided by developed countries does not appear to have agreed continuity into the future. Therefore, although for example, Japan had provided some aid to help countries revise their NBSAPs, two respondents argued that the lack of baseline indicators for some projects may militate against continued support from Japan. Similarly, the EU and the US appear to be limited by the economic downturn in increasing funding. One respondent mentioned that while the EU had recently committed about \$US 25 million to Critical Ecosystem Partnership Fund (CEPF) that supports 1700 civil society organizations and 23 hotspots covering part of 60 countries around the world, this would not be sufficient to achieve the levels of conservation and management action necessary. Most concerning to multiple respondents was that the financing mechanism keeps getting pushed to future meetings. The Nagoya meeting in 2010 left the funding issue to COP11 in 2012, which further pushed the issue to COP12 in 2014-where only limited resolution achieved. Weak leadership on the part of developed states in arguing for sustained increases in funding may seriously threaten ultimate achievement on Aichi Targets in developing countries.

\section{Discussion}

Four unique governance opportunities emerged through the interviews which can augment current efforts to improve developing country efforts towards the Aichi Targets. These can involve repackaging the biodiversity problem, developing guidance for national NBSAPs, clearer assistance on mainstreaming and governing nexus issues in biodiversity governance, and finally strengthening the financial system.

\subsection{Reframing the Biodiversity Problem}

"Biodiversity loss" figures prominent in the language of the targets and assessments in the CBD. The 2010 Target and the Strategic Goal A of the Aichi target both aim to halve the rate of biodiversity loss [53]. As highlighted above, some respondents considered that the language of "biodiversity loss", rather than linking biodiversity to ecosystem services and sustainable development could limit attention to the problem of biodiversity loss in developing countries. This is particularly true for non-environmental ministries and local communities. Changing the language from biodiversity loss to more positive terms can offer opportunities to change public perceptions and attitudes toward biodiversity conservation. Expanded work in understanding how public awareness of biodiversity is shaped can be undertaken through efforts on achieving Aichi Target 1 (increase public awareness about the values of biodiversity). While discussion about Aichi Target 1 was limited at the Hyderabad COP, and fared little better at COP12, it is an area ripe for attention. 


\subsection{Guidance for NBSAPS}

More attention needs to be spent on getting the most out of the NBSAPs in developing countries. The first generation of NBSAPs was held back by not having the involvement of relevant ministries and stakeholders, by technical problems, and lack of political will and funding [18]. These problems may be more serious in the second generation development where NBSAPs had to account for the specifics of the 2011-2020 Strategic Plan. Of 194 parties (countries) to the CBD, only 35 countries (post-Nagoya) had submitted NBSAP revised versions that connected with the Strategic Plan [54]. So far, there has not been significant effort in improving the NBSAP process in the post-Nagoya period. The role of relevant stakeholders in the development of NBSAPs cannot be overemphasized if developing countries are to achieve Aichi target by 2020. There is need to spell out how relevant ministries (led by the Ministry of the Environment) could participate meaningfully in the planning and developmental process of the NBSAP with clear understanding and specific role across different sectors to achieve an inclusive biodiversity policy. For example, in China, the Ministry of Environmental Protection (MEP) is working jointly with more than 20 ministries and departments in updating their NBSAP to implement their strategic plan for 2011-2030. How effective NBSAPs are as a tool in the implementation of the strategic plan is as yet unknown, in view of lack of comprehensive assessments in developing countries. A concerted effort and coordinated approach is required to speed up the assessments, harmonization and development processes in developing countries.

While good biodiversity governance cannot on its own solve the policy fragmentation holding back efforts in many developing countries, NBSAPs must take account of this fragmentation and deal with it. In fact, the Aichi Targets themselves may actually foster policy fragmentation rather than reducing it or providing ways to deal with it. Many respondents worried that governments would pursue a few Aichi Targets while ignoring the holistic picture. While the final decision at the Hyderabad COP emphasized the importance of indicators in the implementing the Aichi biodiversity targets in developing countries [55], there is still no clear guideline to facilitate national action. The result is a lack of clarity on how to interpret global targets at national and local levels. This creates a painstakingly slow process of deciding which target to pursue, articulating the target for the national level, and then integrating it into the policy context. If national targets are not specifically clarified and established within the framework of the CBD - how these targets can be linked to the implementation of the Aichi biodiversity targets remain unclear. While the direction toward implementation by the parties should be guided under a specific purpose of defined targets [56], Aichi biodiversity targets could suffer the same fate as their precursors (the 2010 biodiversity targets) where lack of a desired "end point" and clarity undermined their achievement [57-59].

\subsection{Assistance on Mainstreaming/Governing Nexus}

The whole effort should not focus on developing NBSAPs only but how to mainstream them into local and national sectoral strategies is key to implementation of objectives of the CBD in developing countries. According to Article 6b, "Integrate, as far as possible and as appropriate, the conservation and sustainable use of biological diversity into relevant sectoral or cross-sectoral plans, programs and policies" [60], p. 4). However, there is lack of clarification on how to achieve this objective in view of 
conflicting national agendas, particularly where priority and resource availability play an important role. One of the fundamental points raised by the respondents is that competing priorities for limited resources particularly in many poor countries in an effort to achieve the Aichi target can be very challenging. One respondent argued that how Aichi target is prioritized as part of national agenda when the same Aichi target is competing with a bigger national agenda which requires budget allocation remains to be clarified, and it may be impossible to abandon original agenda because of Aichi target. Governing this process without interfering or overriding national agenda is very important. Though some respondents suggested that a requirement like this can get mainstreamed into national planning policies that cut across various sectors but it will depend on the availability of the resources and the rate at which can be accommodated. Moreover, they emphasized the need to have a clearer understanding between various aspects of biodiversity and sectoral development program of the government particularly in addressing the fundamental challenges related to biodiversity conservation and poverty alleviation.

\subsection{Strengthening Financial System}

Finally, funding is an anchor for all of the process above. Without a financial system in place, respondents were skeptical of the possibility of achieving the other Aichi Targets. Despite Target 20 focused on financing, the issue has been continually pushed into the future. While this problem is often recognized by the parties [55], little has been accomplished to help developing countries meet the Aichi Targets. Respondents suggested a more complex picture of this situation. One respondent emphasized that there is a difference in the funding relationship between donors and different developing countries. For example, the interest of advanced economies such as China, India, Brazil and their relationships with donors are different from those of, e.g., Zambia, Mozambique, Philippine and other less developed countries.

The problem is then that aid may not be spent in the most effective manner. In 2008, Brazilian and Mexican governments are the principal sources of funds for biodiversity conservation in Latin America [2]. For example, $60 \%$ of the total funds were donated by the governments, and 15\% was received from the donors. As another example, Brazil and India were the largest recipients of biodiversity related aid in 2011, receiving $12 \%$ and $12.5 \%$, respectively [61]. South East Asian, African countries and some Latin American states represent most of the severely underfunded countries for biodiversity conservation [31], reinforcing the arguments of the respondents and part of the speech of the Indian Prime Minister that policymakers should prioritize and provide all the necessary supports (financial, technical and human) to these regions in order to meet the CBD targets. The whole argument boils down to the need for a realignment of the negotiation country groups that takes into account the individual country capacities and interests within the G77. Donor countries should be encouraged to mobilize resources as universal agreement may not satisfy all countries due to their different needs and aspirations. It is hoped that the new long-term GEF 2020 strategy announced at the COP11 Conference, with bilateral donors can consider these important elements in their financial mechanism to facilitate implementation of Aichi targets in developing countries. 


\section{Conclusions and Policy Implication}

Following COP 11 and 12, there are a range of policy developments that can help pursue progress on the Aichi Targets in developing countries. Simply stated these are:

- Attention on the 2015 targets which may be lagging. The coming into effect of the Nagoya Protocol and a robust system of NBSAPs are necessary to enable progress after COP12. In addition, focus on other foundational targets could be pivotal in establishing the conditions for success. Target 1 (increasing awareness) and Target 20 (financial mechanism) would be important goals for significant new emphasis. As noted by respondents above, increasing awareness may mean approaching biodiversity in a different way and while not forgetting about "loss" emphasizing the role of ecosystem services in development.

- A comprehensive financial arrangement needs to be prioritized. While the 2011-2020 period was able to see an increase in aid, as noted above, this was largely a result of combining biodiversity funding with other projects. This is neither a good not a bad thing for biodiversity, it is an issue which requires a more comprehensive approach. Developing a funding approach that creates local markets for ecosystem services (building on the Nagoya Protocol), increases international funding, and clarifies best practices for funding biodiversity and other processes (such as climate change, development, water, etc.) is key. This includes developing funding not simply for protected areas but for protected area systems that include both land and marine areas.

- Capacity buildings for NBSAPs are crucial. First generation NBSAPs did not create the model that they could have because the processes were often developed too narrowly and political will to implement its initiatives was lacking. Developing countries can be helped significantly by providing guidance and incentives for CBD focal points to engage with other stakeholders and help build political will. In addition, the science community (including the developing IPBES) needs to provide clearer ways for states to translate the global to national level conditions in the most effective way possible.

- Create a more rigorous clearinghouse mechanism for examining biodiversity policy experimentation. As one respondent commented "Right now what we need is to mobilize resources so that the developing countries can scope out their programs that work to meet the Aichi Targets, and they need money for that". A more rigorous process for collecting information and evaluating it based on unambiguous evidence could be very helpful as developing countries create their NBSAPs and implement biodiversity policies. Funding south-south cooperation could facilitate this effort or perhaps this is a role for the developing IPBES. Although the approach IPBES will take towards facilitating science is still being determined, there may be some important opportunities on issues such as indigenous knowledge. Regardless, this should fit into the funding conditions discussed above.

- Developing a plan for technology transfer. While UNEP has made technology transfer a key contribution of its efforts since the development of the Bali Strategic Plan [62,63], there is not yet clear effort in this regard under the CBD. Respondents were clear that appropriate technology transfer should be decided on a case-by-case basis; depending on the issue. Unfortunately, this once again is a problem of infrastructure which is often lacking in 
developing countries. Developing a plan and strategy for assessing technology, implementing it in effective and equitable ways, and finally fostering the transfer remains desiderata.

\section{Acknowledgments}

All interview participants at COP 11, October 2012, Hyderabad, India, are gratefully acknowledged for their valuable time and contributions. We are also grateful to Ashna Mukhi in coding and assisting with the paper. Special thanks to the three anonymous reviewers and Sam Johnston for their comments and helpful guidance on earlier version of the manuscript. Casey Stevens thanks the Japanese Society for Promotion of Science for assistance while working on this project. This paper was only originally presented as a working paper with the Earth System Governance.

\section{Author Contributions}

Ademola A. Adenle designed the study and conducted the interviews. Ademola A. Adenle and Casey Stevens analyzed and interpreted the data. Ademola A. Adenle, Casey Stevens and Peter Bridgewater wrote the paper. All the three authors have read and approved the paper.

\section{Appendix-Set of Interview Questions}

Interviews involved a set of open-ended questions for respondents, with the ability for the interviewer to deviate from that set or follow-up with additional questions as necessary. While this basic set of questions changed based upon the individual and their position, this appendix provides some common questions which were posed to multiple participants.

(1). What is the national framework for biodiversity conservation in (Country)?

(2). How is biodiversity financed in (Country)?

(3). In terms of financial resources, how do you generate funds to support the project of biodiversity conservation?

a. Are you getting resources from outside, from external donors towards developing the biodiversity framework and achieving the Aichi targets? How do you secure these resources?

(4). Do you think (Country) would be able to achieve the Aichi targets by 2020 ?

a. What are the hindrances that may affect the conservation of biodiversity and achieving the Aichi targets by 2020 ?

b. Are there any problems in (Country) in planning for the Aichi targets?

(5). So in terms of new technology, what sort of technology would be appropriate to assist biodiversity efforts?

(6). How can various stakeholders (business, other ministries, etc.) be included in biodiversity efforts?

\section{Conflicts of Interest}

The authors declare no conflict of interest. 


\section{References}

1. Gari, J.A. Biodiversity Conservation and Use: Local and global considerations. In Science, Technology and Development Discussion Paper No. 7, Center for International Development and Belfer Center for Science and International Affairs; Harvard University: Cambridge, MA, USA, 1999.

2. Flores, M. Protected Areas. In The Importance of Biodiversity and Ecosystem in Economic Growth and Equity in Latin America and the Caribbean: An Economic Valuation of Ecosystem; Bovarnick, A., Alpizar, F., Schnell, C., Eds.; United Nations Development Programme (UNDP): New York, NY, USA, 2010; pp. 203-237.

3. Report of the Sixth Meeting of the Conference of the Parties to the Convention on Biological Diversity. Available online: https://www.cbd.int/doc/meetings/cop/cop-06/official/cop-06-20en.pdf (accessed on 20 December 2014).

4. Adenle, A.A. Failure to achieve 2010 biodiversity's target in developing countries: How can conservation help? Biodivers. Conserv. 2012, 21, 2435-2442.

5. Butchart, S.H.; Walpole, M.; Collen, B.; van Strien, A.; Scharlemann, J.P.; Almond, R.E.; Baillie, J.E.; Bomhard, B.; Brown, C.; Bruno, J.; et al. Global biodiversity: Indicators of recent declines. Science 2010, 328, 1164-1168.

6. United Nations. Millennium Development Goals Report 2012; UN Publications: New York, NY, USA, 2012.

7. Fisher, M. 2010 and all that-Looking Forward to Biodiversity Conservation in 2011 and beyond. Oryx 2009, 43, 449-450.

8. The Economics of Ecosystems and Biodiversity (TEEB). The Economics of Ecosystems and Biodiversity: An Interim Report; European Communities: Cambridge, UK, 2008.

9. Leone, F. Earth Negotiations Bulletin. A Reporting Service for Environment and Development Negotiations. In Proceedings of the Summary of the Tenth Conference of the Parties to the Convention on Biological Diversity, Nagoya, Japan, 18-29 October 2010; p. 9. Available online: http://www.iisd.ca/download/pdf/enb09544e.pdf (accessed on 20 December 2014).

10. McCarthy, D.P.; Donald, P.F.; Scharlemann, J.P.; Buchanan, G.M.; Balmford, A.; Green, J.M.; Bennun, L.A.; Burgess, N.D.; Fishpool, L.D.; Garnett, S.T.; et al. Financial costs of meeting global biodiversity conservation targets: Current spending and unmet needs. Science 2012, 338, 946-949.

11. Miller, D.C.; Agrawal, A.; Roberts, J.T. Biodiversity Governance, and the Allocation of International Aid for Conservation. Conserv. Lett. 2013, 6, 12-20.

12. Wood, A.; Stedman-Edward, P.; Mang, J. Root Causes of Biodiversity Loss; Earthscan Publications: London, UK, 2000.

13. Nijman, V. An overview of international wildlife trade from Southeast Asia. Biodivers. Conserv. 2010, 19, 1101-1114.

14. Millennium Ecosystem Assessment. Ecosystems and Human Well-Being: Biodiversity Synthesis; World Resources Institute: Washington, DC, USA, 2005.

15. Lenzen, M.; Moran, D.; Kanemoto, K.; Foran, B.; Lobefaro, L.; Geschke, A. International trade drives biodiversity threats in developing nations. Nature 2012, 486, 109-111. 
16. Lenzen, M.; Moran, D.; Bhaduri, A.; Kanemoto, K.; Bekchanov, M.; Geschke, A.; Foran, B. International trade of scarce water. Ecol. Econ. 2013, 94, 78-85.

17. UNEP-CBD. United Nations Environment Programme-Convention on Biological Diversity. Strategic Plan. Avaiable online: http://www.cbd.int/decision/cop/default.shtml?id=7200 (accessed on 20 December 2014).

18. Prip, C.; Gross, T.; Johnston, S.; Vierros, M. Biodiversity Planning. In An Assessment of National Biodiversity Strategies and Action Plans; United Nations University Institute of Advanced Studies: Tokyo, Japan, 2010.

19. Swiderska, K. Mainstreaming Biodiversity in Development Policy and Planning: A Review of Country Experience; Biodiversity and Livelihoods Group International Institute for Environment and Development (IIED): London, UK, 2002.

20. Agrawal, A.; Redford, K. Poverty, Development and Biodiversity Conservation: Shooting in the Dark? Wildlife Conservation: New York, NY, USA, 2006.

21. Adams, W.M.; Aveling, R.; Brockington, D.; Dickson, B.; Elliott, J.; Hutton, J.; Roe, D.; Vira, B.; Wolmer, W. Biodiversity Conservation and the Eradication of Poverty. Science 2004, 306, 1146-1149.

22. Ostrom, E. Governing the Commons; University of Cambridge Press: Cambridge, UK, 1990.

23. Hill, R.; Halamish, E.; Gordon, I.J.; Clark, M. The maturation of biodiversity as a global social-ecological issue and implications for future biodiversity science and policy. Futures 2013, $46,41-49$.

24. Krishna, V.V.; Drucker, A.G.; Pascual, U.; Raghu, P.T.; King, E.D.I.O. Estimating compensation payments for on-farm conservation of agricultural biodiversity in developing countries. Ecol. Econ. 2013, 87, 110-123.

25. Schomers, S.; Matzdorf, B. Payments for ecosystem services: A review and comparison of developing and industrialized countries. Ecosyst. Serv. 2013, 6, 16-30.

26. Padmanabhan, M.; Jungcurt, S. Biocomplexity-conceptual challenges for institutional analysis in biodiversity governance. Ecol. Econ. 2012, 81, 70-79.

27. Farmar-Bowers, Q.; Lane, R. Understanding farmers' strategic decision-making processes and the implications for biodiversity conservation policy. J. Environ. Manag. 2009, 90, 1135-1144.

28. Dobson, A. Monitoring global rates of biodiversity change: Challenges that arise in meeting Convention on Biological Diversity (CBD) 2010 goals. Philosophical Transanctions of the Royal Society of London. Biol. Sci. 2005, 360, 229-241.

29. Santamaria, L.; Mendez, P.B. Evolution in biodiversity policy-current gaps and future needs. Evol. Appl. 2012, 5, 202-218.

30. Halpern, B.S.; Pyke, C.R.; Fox, H.E.; Haney, J.C.; Schlaepfer, M.A.; Patricia Zaradic, P. Gaps and mismatches between global conservation priorities and spending. Conserv. Biol. 2006, 20, 50-64.

31. Waldron, A.; Mooers, A.O.; Miller, D.C.; Nibbelink, N.; Redding, D.; Kuhn, T.S.; Roberts, J.T.; Gittleman, J.L. Targeting global conservation funding to limit immediate biodiversity declines. Proc. Natl. Acad. Sci. USA 2013, 110, 12144-12148.

32. Miller, D.C. Explaining Global Patterns of International Aid for Linked Biodiversity Conservation and Development. World Dev. 2014, 59, 341-359. 
33. Barber, P.H.; Ablan-Lagman, M.C.A.; Ambariyanto Berlinck, R.G.S.; Cahyani, D.; Crandall, E.D.; Ravago-Gotanco, R.; Cahyani, D.; Juinio-Meñez, M.A.; Mahardika, G.N.; Shanker, K.; et al. Advancing Biodiversity Research in Developing Countries: The Need for Changing Paradigms. Bull. Marine Sci. 2014, 90, 1-24.

34. Yin, R.K. Case study research: Design and methods. In Applied Socialresearch Methods Series, 3rd ed.; Sage Publications: New York, NY, USA, 2003; Volume 5, p. 111.

35. Clark, R.E., Feldon, D., van Merrienboer, J.J.G., Yates, K., Early, S., Eds. Cognitive task analysis. In Handbook of Research on Educational Communications and Technology, 3rd ed.; Lawrence Erlbaum Associates: Mahwah, NJ, USA.

36. Dalal, S.; Khodyakov, D.; Srinivasan, R.; Straus, S.; Adams, J. ExpertLens: A system for eliciting opinions from a large pool of non-collocated experts with diverse knowledge. Technol. Forecast. Soc. Chang. 2011, 78, 1426-1444.

37. International Union for Conservation of Nature, United Nations Environment Programme (IUCN, UNEP). The World Database on Protected Areas (WDPA); United Nations Environment Programme-World Conservation Monitoring Centre (UNEP-WCMC): Cambridge, UK, 2009.

38. UNEP-CBD. United Nations Environment Programme - Convention on Biological Diversity. Quick Guide to Target 11 of the Aichi Biodiversity Targets. Available online: http://www.cbd.int/ doc/strategic-plan/targets/T11-quick-guide-en.pdf (accessed on 20 December 2014).

39. Mother Earth. Proposal for a Law of Mother Earth. Plurinational State of Bolivia. Available online: http://boliviadiary.files.wordpress.com/2011/06/ley-madre-tierra-en-inglesversion-final.pdf (accessed on 20 December 2011).

40. United Nations Environment Programme. Protected Planet Report 2012: Tracking Progress Towards Global Targets for Protected Areas; United Nations Environmnet Programme World Conservation Monitoring Center: Cambridge, UK, 2012.

41. Woodley, S.; Bertzky, B.; Crawhill, N.; Dudley, N.; Londono, J.M.; MacKinnon, K.; Redford, K.; Sandwith, T. Meeting Aichi Target 11: What Does Success Look Like for Protected Area Systems? Parks 2012, 18, 21-34.

42. United Nations Environment Programme-World Conservation Monitoring Centre (UNEP-WCMC) National and Regional Networks of Marine Protected Areas; UNEP-WCMC: Cambridge, UK, 2008.

43. Joppa, L.; Visconti, P.; Jenkins, C.; Pimm, S. Achieving the convention on biological diversity's goals for plant conservation. Science 2013, 341, 1100-1103.

44. Secretariat of the Convention on Biological Diversity. Mainstreaming Biodiversity into National Sectoral and Cross-Sectoral Strategies, Policies, Plans, and Programs, NBSAP Training Modules Version 2.1-Module 3; Convention on Biological Diversity (CBD): Montreal, QC, Canada, 2011.

45. Chasek, P. Confronting Environmental Treaty Implementation Challenges in the Pacific Islands; East-West Center: Honolulu, HI, USA, 2010.

46. Union for Ethical BioTrade. Biodiversity Barometer 2013; UEBT: Amsterdam, The Netherlands, 2013.

47. Palmer, C.; di Falco, S. Biodiversity, poverty, and development. Oxf. Rev. Econ. Policy 2012, 28, $48-68$.

48. Gatzweiler, F.W. Organizing a public ecosystem service economy for sustaining biodiversity. Ecol. Econ. 2006, 59, 296-304. 
49. Parker, C.; Cranford, M.; Oakes, N.; Leggett, M. The Little Biodiversity Finance Book; Global Canopy Programme: Oxford, UK, 2012.

50. Organisation for Economic Co-operation and Development (OECD). OECD DAC Statistics: Biodiversity-Related Aid; OECD: Paris, France, 2013.

51. The World Bank. Expanding Financing for Biodiversity Conservation: Experiences from Latin America and the Caribbean; The World Bank: Washington, DC, USA, 2012.

52. Chandra, A.; Idrisova, A. Convention on Biological Diversity: A review of national challenges and opportunities for implementation. Biodivers. Conserv. 2011, 20, 3295-3316.

53. Aichi Biodiversity Targets. Available online: https://www.cbd.int/sp/targets/ (accessed on 20 December 2013).

54. CBD. Convention on Biological Diversity. Latest NBSAPs. Available online: http://www.cbd.int/ nbsap/about/latest (accessed on 20 December 2014).

55. Report of the Eleventh Meeting of the Conference of the Parties to the Convention on Biological Diversity. Available online: http://www.cbd.int/doc/meetings/cop/cop-11/official/cop-11-35en.pdf (accessed on 20 December 2014).

56. Pisupati, B.; Rubian, R. MDG on Reducing Biodiversity Loss and the CBD's 2010 Target; United Nations University-Institute of Advanced Studies (UNU-IAS): Yokohama, Japan, 2008.

57. Mace, G.; Baillie, J.E. The 2010 Biodiversity Indicators: Challenges for Science and Policy Conservation Biology. Conserv. Biol. 2007, 6, 1406-1413.

58. Harrop, S.R.; Pritchard, D.J. A hard instrument goes soft: The implications of the Convention on Biological Diversity's current trajectory. Global Environ. Chang. 2011, 21, 474-480.

59. Johannsdottir, A.; Cressewell, I.; Bridgewater, P. The Current Framework for International Governance of Biodiversity: Is It Doing More Harm than Good? RECIEL 2010, 19, 139-149.

60. Global Environment Facility-United Nations Environment Programme-Convention on Biological Diversity (GEF/UNEP/CBD). Mainstreaming Biodiversity into Sectoral and Cross-Sectoral Strategies, Plans and Programmes; Module B-3. Available online: https://www.cbd.int/doc/ training/nbsap/b3-train-mainstream-en.pdf (accessed on 20 December 2007).

61. BIP. Biodiversity Indicator Partnership. Indicator relationship to main Aichi Biodiversity target. Available online: http://www.bipindicators.net/oda (accessed on 20 December 2014).

62. United Nations Environment Programme (UNEP). Bali Strategic Plan for Technology Support and Capacity-Building; UNEP: Nairobi, Kenya, 2005.

63. United Nations Environment Programme (UNEP). Technology Transfer and Cooperation under the Convention on Biological Diversity: Towards More Effective Implementation; UNEP: Nairobi, Kenya, 2010.

(C) 2014 by the authors; licensee MDPI, Basel, Switzerland. This article is an open access article distributed under the terms and conditions of the Creative Commons Attribution license (http://creativecommons.org/licenses/by/4.0/). 